Jay Pee M. Amable, MD

Lily L. Sia-Vargas, MD

\section{Department of Otorhinolaryngology} Head and Neck Surgery

University of the East - Ramon Magsaysay Memorial Medical Center, Inc
Correspondence: Dr. Jay Pee M. Amable Department of Otorhinolaryngology-Head and Neck Surgery 5th floor ENT Office Charity Bldg., UERMMMCI 64 Aurora Blvd. Brgy Doña Imelda, Quezon City 1113 Philippines

Phone: (632) 7150861 local 257

E-mail: jpamablemd@gmail.com

Reprints will not be available from the authors.

The authors declared that this represents original materia that is not being considered for publication or has not been published or accepted for publication elsewhere, in full or in part, in print or electronic media; that the manuscript has been read and approved by all the authors, that the requirements for authorship have been met by each author, and that each author believes that the manuscript represents honest work.

Disclosures: The authors signed disclosures that there are no financial or other (including personal) relationships, intellectual passion, political or religious beliefs, and institutional affiliations that might lead to a conflict of interest.

No live animals were used in testing this instrument.

Presented at the PSO-HNS 2013 Annual convention Surgical Innovation/Instrumentation Contest (1st place), December 3, 2013 at Sofitel Philippine Plaza Hotel, CCP Complex, Manila.

\title{
A Myringotomy and Ventilating Tube Applicator: New Look at a Five-Century-Old Procedure
}

\begin{abstract}
Objectives: To fabricate a single instrument that can be used to perform myringotomy and insert a pressure equalizing tube at almost the same time.

\section{Methods:}

Design: Surgical Instrumentation

Setting: Tertiary Private Hospital

Subject: A chicken egg membrane was used as a tympanic membrane model
\end{abstract}

Results: The fabricated instrument was able to perforate the egg membrane and apply the modified polyethylene pressure equalizing tube in less than one minute without complications.

Conclusion: The prototype applicator can facilitate myringotomy and pressure equalizing (PE) tube insertion at only a fraction of the time it usually takes to do the standard myringotomy and subsequent ventilating tube insertion.

Keywords: Myringotomy, pressure equalizing tube, ventilating tube, acute otitis media, otitis media with effusion, polyethylene tube

Myringotomy with pressure equalizing (PE) or ventilating tube (VT) insertion is one of the most common ambulatory ear surgeries performed in the United States with 19.7 thousand (92.6\%) performed in the out-patient setting in 2012 alone.' It is a relatively rapid procedure and may be performed under topical anaesthesia. The standard procedure is to perform myringotomy initially, then insert the pressure equalizing or ventilating tube subsequently. The myringotomy may cause some pain or discomfort to the patient and affect his/her cooperation when the tube insertion is done next. Moreover, commercial tubes are costly and cannot be readily obtained in many settings. We describe our fabricated applicator and surgical technique to facilitate myringotomy with PE tube insertion and reduce operative time using an egg model. 


\section{SURGICAL INNOVATIONS AND INSTRUMENTATION}

\section{METHODS}

\section{Materials:}

a. Alligator forceps

b. Medical grade Polyethylene tube, PE 205

c. Metal stopper from leftover titanium mesh

d. Chicken Eggs

e. Cyanoacrylate (super glue)

f. Aural speculum

g. Straight forward endoscope $0^{0}, 4 \mathrm{~mm}$

h. Frazer suction tip \# 3 and suction machine
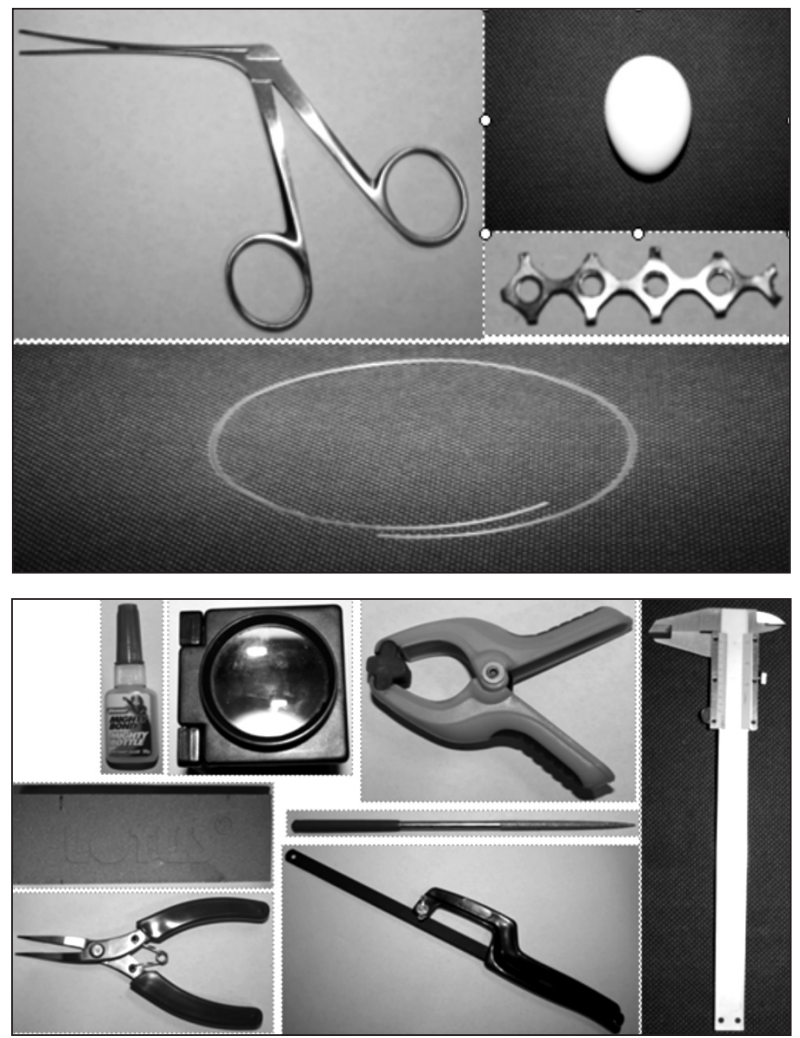

Figure 1. Materials, Tools and Equipment

\section{Tools and equipment:}

a. $254 \mathrm{~mm}$ Hacksaw

b. Carbide stone

c. Long nose pliers

d. Round file

e. Blade or sharp scissors

f. Vernier caliper

g. Plastic Grip

h. Magnifying lens

i. Flame burner or lighter

\section{FABRICATION}

\section{MYRINGOTOMY TUBE APPLICATOR}

1. The alligator forceps was grasped with the plastic grip. The distal tip of the alligator forceps was cut to remove $1 \mathrm{~cm}$ using a hacksaw.

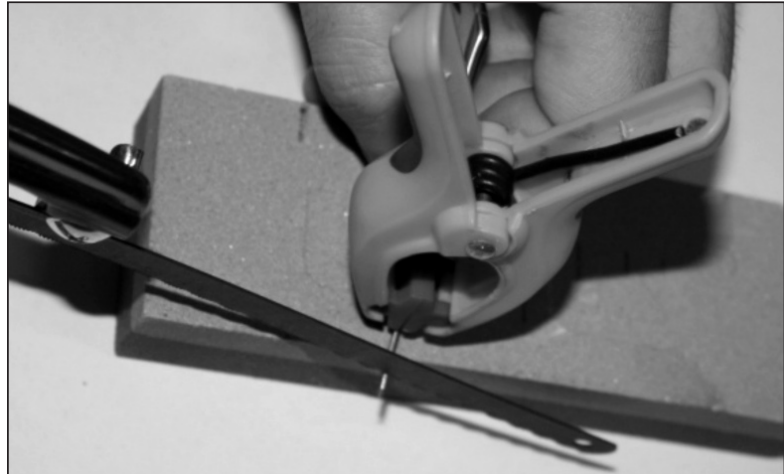

Figure 2. Cutting the distal tip of the alligator forceps using a hacksaw

2. The cut tip of the alligator forceps was sharpened using a carbide stone.

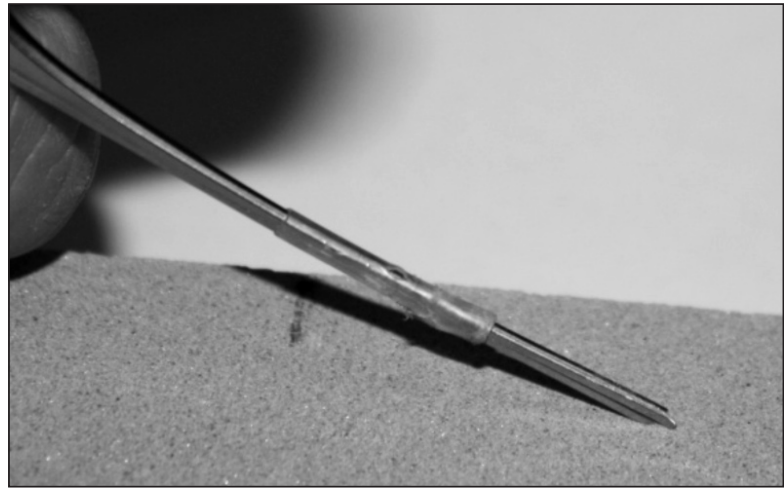

Figure 3. Sharpening the cut tip of the alligator forceps on a carbide stone

3. The corners of the shaft were blunted using a round file.

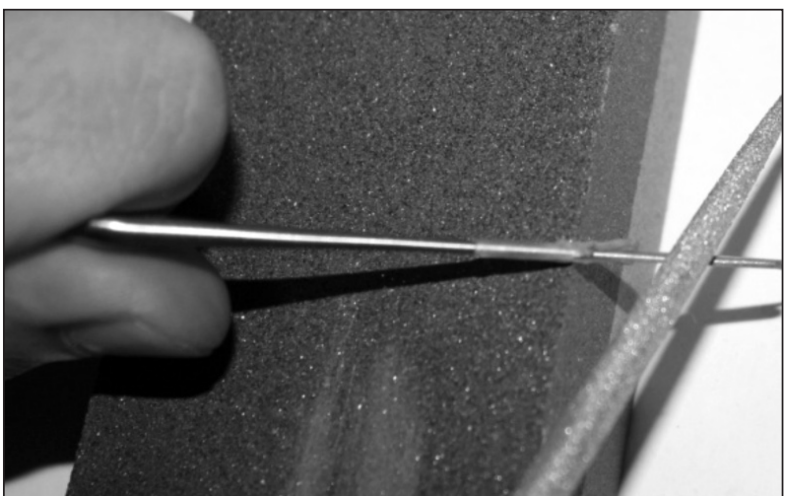

Figure 4. Blunting the corners of the shaft with a round file. 


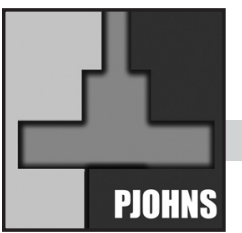

\section{SURGICAL INNOVATIONS AND INSTRUMENTATION}

Philippine Journal Of Otolaryngology-Head And Neck Surgery

Vol. 30 No. 2 July - DeCEMBER 2015

4. A metal stopper was attached on top of the shaft near the

\section{RESULTS}

sharpened edge using super glue.

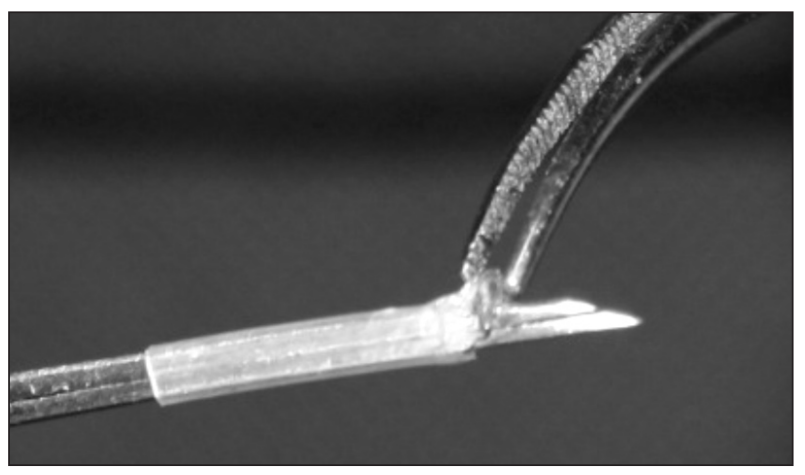

Figure 5. Attaching metal stopper on top of shaft using super glue

\section{PRESSURE EQUALIZING TUBE}

1. A $6 \mathrm{~mm}$ segment of polyethylene with a bevelled edge was cut using a blade or sharp scissors.

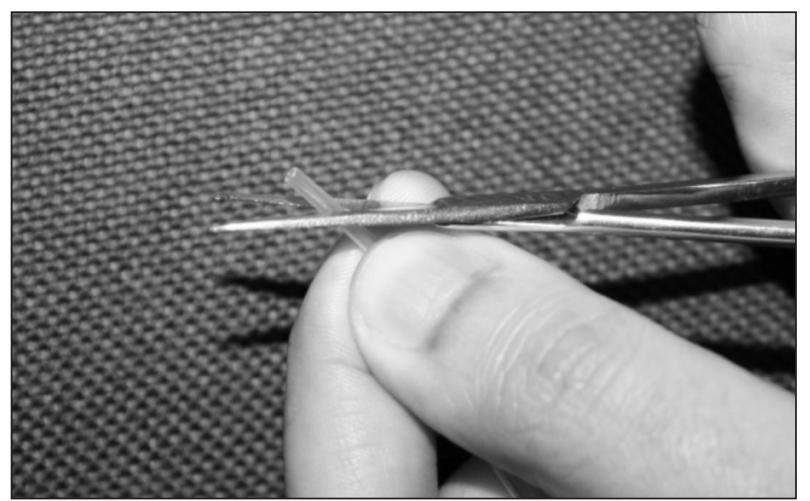

Figure 6. Cutting the polyethylene tube

2. The non-bevelled edge was melted over an open flame until the tube was about $4 \mathrm{~mm}$ in height and the melted edge rolled up and measured around $4 \mathrm{~mm}$ in diameter, forming a flange.

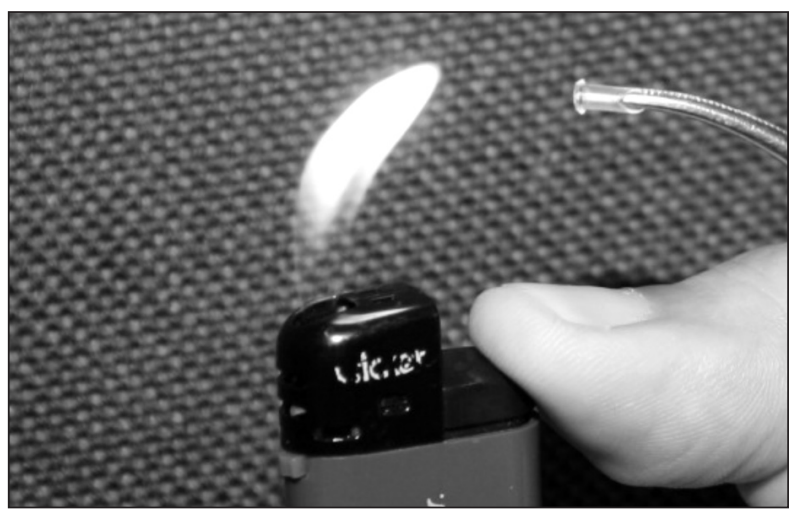

Figure 7. Flanging the tube
1. The plunger was retracted by opening the forceps.
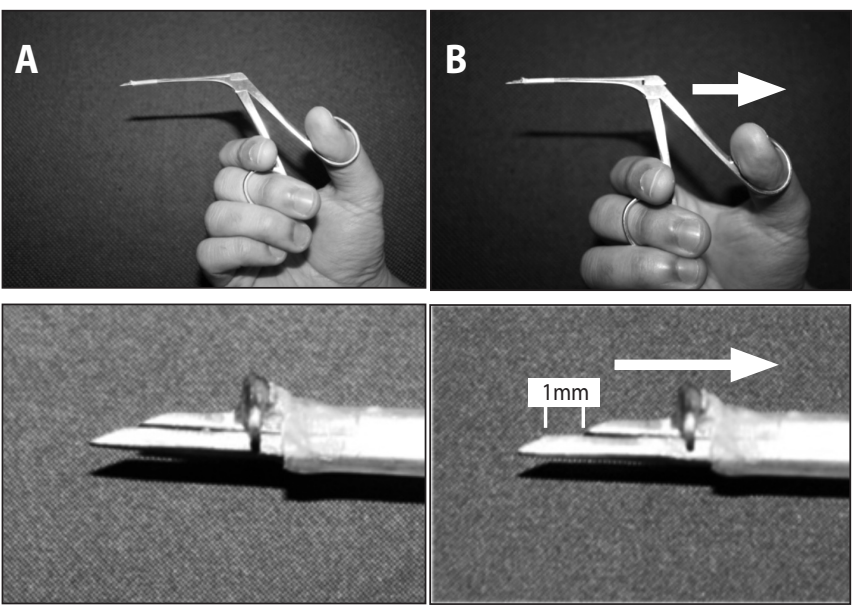

Figure 8 A. Forceps closed (above) with close up of tip (below); B. Forceps opened (above) with close up of tip (below) showing plunger tip retracted from applicator tip.

2. The polyethylene tube was loaded on the applicator.
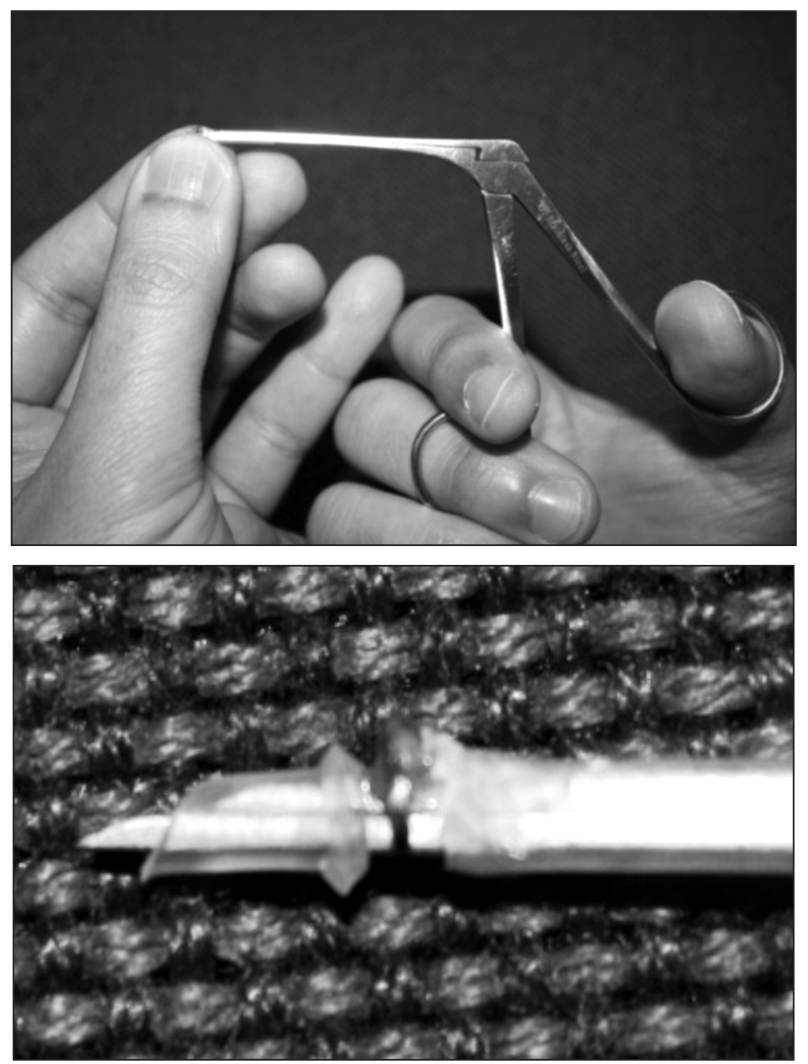

Figure 9. Loading fabricated ventilating tube on applicator 


\section{SURGICAL INNOVATIONS AND INSTRUMENTATION}

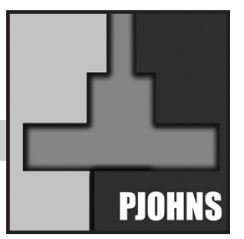

3. The loaded forcep applicator was inserted through an ear speculum abutting the exposed membrane of a partly-shelled chicken egg under endoscopic guidance.

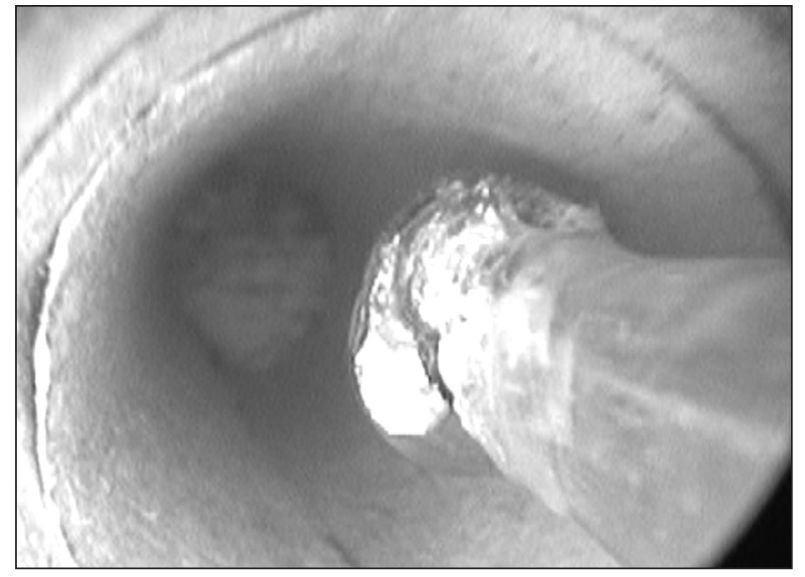

Figure 10. Insertion of loaded forcep applicator through ear speculum

4. The exposed membrane of a partly-shelled chicken egg was pierced making sure the flange touched the membrane lightly and then the forceps were closed, pushing the tube and leaving it in the membrane.

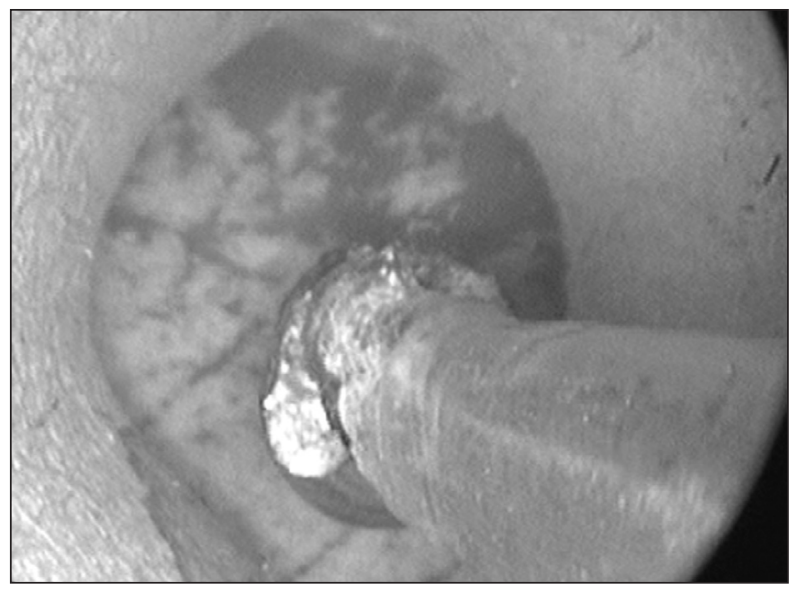

Figure 11. Myringotomy and ventilating tube insertion
5. The forceps applicator was retracted, and fluid was suctioned through the ventilating tube. The procedure was repeated 10 times with similar results and without complications.
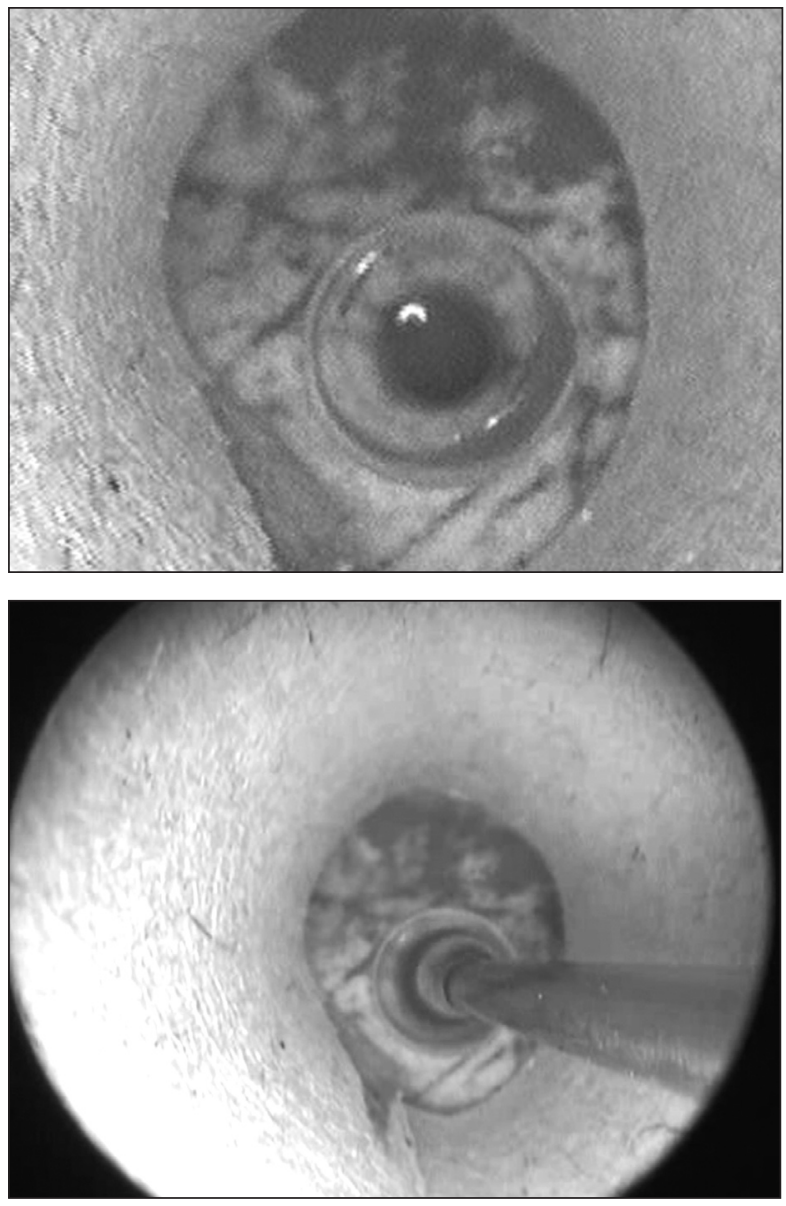

Figure 12. Suctioning through patent ventilating tube.

\section{DISCUSSION}

Otitis media with effusion is a common disorder of the middle ear caused by poor clearance of middle ear fluid usually following an episode of acute otitis media. In our current clinical practice guidelines $(\mathrm{CPG})$, a 3-month waiting period of conservative management is preferred. ${ }^{2}$ However, in cases where there is persistence of disease and significant hearing loss or for children with recurrent episodes of AOM usually defined as three or more episodes of AOM in 6 months or four or more episodes in 12 months, myringotomy with pressure equalizing (PE) or ventilating tube (VT) insertion is the usual management. ${ }^{3} \mathrm{It}$ is also performed in adults and may be done under topical anesthesia. 


\section{VENTILATION TUBES}

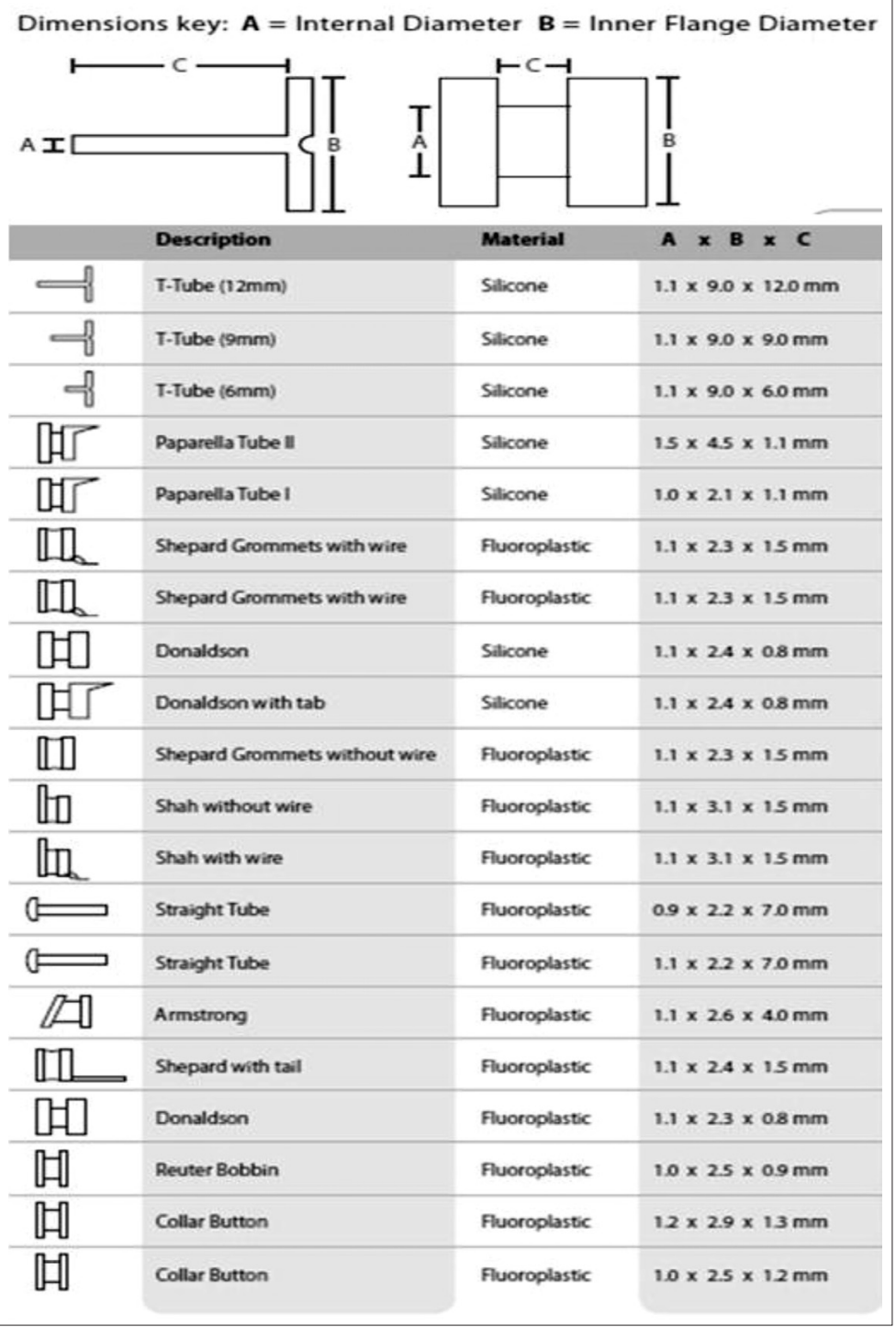

Figure 13. Reproduced with permission from Network Medical Products Ltd. Coronet House, Kearsley Road, Ripon, North Yorkshire HG4 2SG, UK.

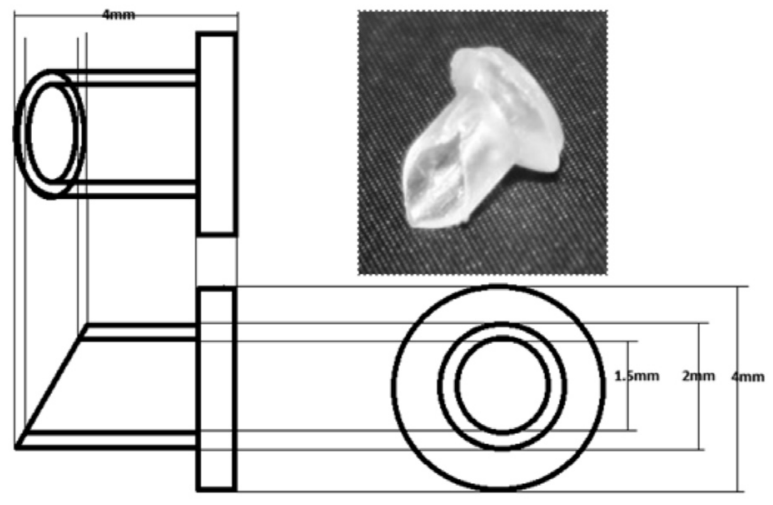

Figure 14. Dimensions of fabricated tube.
Myringotomy is a very old procedure. The first recorded myringotomy was in 1649 when Jean Riolan the Younger accidentally perforated the eardrum of a patient complaining of ear pain. Astley Cooper presented two papers to the Royal Society in 1801; based on his observation that myringotomy could improve hearing. However, due to injudicious use of the procedure, the practice of myringotomy was almost abandoned. ${ }^{4}$ The use of myringotomy was again reintroduced during the $19^{\text {th }}$ century and is presently the most common surgical procedure in children that requires general anesthesia. ${ }^{5}$ Innovations have been introduced and different types of pressure equalizing (PE) tubes are currently available in the market. ${ }^{6}$ (Figure 13)

The area of the middle ear cavity on the average is 2 $\mathrm{cm}^{3}$ and the widest diameter does not exceed $10 \mathrm{~mm}$. The dimensions of the tympanic membrane along its two major perpendicular axes are 9 to $10 \mathrm{~mm}(0.35$ to $0.39 \mathrm{in})$ and 8 to $9 \mathrm{~mm} .{ }^{7}$ With this, it is possible to create an instrument that can serve the purpose of perforating and applying a tube to equalize the pressure in the middle ear and drain fluid from the cavity.

The length of the sharp portion of the fabricated applicator to the metal flange is $6 \mathrm{~mm}$ and its widest diameter is $1.5 \mathrm{~mm}$. The dimensions of the fabricated PE tube are $4 \mathrm{~mm}$ in length, $2 \mathrm{~mm}$ outer diameter, $1.5 \mathrm{~mm}$ inner diameter and the flange is $4 \mathrm{~mm}$ in diameter. (Figure 14) The size of the applicator and tube are adequate to perforate and fit a ventilation tube in the tympanic membrane. The $1 \mathrm{~mm}$ forward and backward motion of the upper part of the forceps is sufficient to push the PE tube and release it from the rest of the mechanism.

The standard myringotomy with pressure-equalizing tube insertion is generally performed as follows: Firstly, the anteroinferior portion of the TM is incised using a myringotomy knife perpendicular to the fibers of the membrane. Secondly, the tube is inserted through the perforation using an alligator forceps. With our innovation, both steps were combined to reduce the time it takes to perform the procedure by half. This could therefore minimize discomfort of the patient and allow ease of application.

The entire procedure was endoscopically guided to allow superior visualization of the ear canal and the tympanic membrane. ${ }^{8}$ The upper part of the applicator was simply retracted and the PE tube loaded. The applicator loaded with the PE tube was then inserted through the canal to 
perforate the TM making sure that the flange touched the tympanic membrane. The flange was then pushed forward by closing the forceps and releasing the tube. As the whole contraption was initially retracted, the PE tube was automatically left in place once released. We repeated the procedure 10 times with similar results and no complications.

The procedure was performed on an egg membrane to simulate the tympanic membrane as it also contains fluid and somewhat comparable to the consistency of the tympanic membrane. However, the exact pressure needed to perforate the egg membrane was not measured and may not be similar to that of the tympanic membrane. The pressure needed to perforate an ear drum at the minimum is $5 \mathrm{psi}$; however, $50 \%$ will perforate at 15 psi. ${ }^{9}$ To our knowledge, this is the first report that investigated using egg membrane as a model for prototype myringotomy applicators. Our innovation has yet to be tested on a human subject. However, the test procedure showed that our prototype applicator was able to perforate the membrane and leave the PE tube in place.

With the tube in place, middle ear fluid can be suctioned and middle ear pressure maintained equal with atmospheric pressure. Suctioning was performed in our model to demonstrate patency of the fabricated ventilating tube. Depending on the type and size of tube used, spontaneous extrusion may occur from 12-18 months, ${ }^{3}$ a property we have yet to test using our fabricated tube.

There are several limitations to this study. The ideal size and shape of commercially available tubes which are uniformly beveled and tapered can only be approximated by our method. The most anterior end of the tube may not always conform to the shape of the instrument and may cause difficulty perforating the membrane. The tip of the instrument was also not surgically sharpened, and minute metal fragments may remain. More advanced equipment and tools would allow us to fabricate a better applicator and tube. Following this, the prototype applicator and tube can be tested in human cadaver tympanic membranes and on live subjects. Sterilization by autoclave (forceps applicator) and/or activated Glutaraldehyde solution (applicator and tube) will have to be tested for such a trial.

In conclusion, our prototype forceps applicator and ventilating tube may simplify myringotomy and pressure equalizing (PE) tube insertion and decrease the surgical time to only a fraction of the time needed for the standard procedure, which may take 10-15 minutes. ${ }^{5} \mathrm{It}$ is inexpensive to fabricate and may potentially reduce the total cost of the procedure as well and we recommend considering its development and use especially in low- and middle-income country settings.

\section{REFERENCES}

1. Wier LM, Steiner CA, Owens PL. Surgeries in Hospital-Owned Outpatient Facilities, 2012. HCUP Statistical Brief \#188. February 2015. Agency for Healthcare Research and Quality, Rockville, MD. [cited 2015 Feb] Available from: https://www.hcup-us.ahrq.gov/reports/statbriefs/sb188Surgeries-Hospital-Outpatient-Facilities-2012.jsp

2. Acuin JM, Dela Cruz WE, Navarro-Locsin CG, Reyes-Quintos MRT, Chan AL, Gloria Cruz TLI, Enriquez HM, Llamanzares TP. Philippine Society of Otolaryngology-Head and Neck Surgery Clinical Practice Guidelines on Acute Otitis Media, 2006.

3. Cassebrandt ML, Mandell EM. Acute otitis media and otitis media with effusion. In: Flint PW, Haughey BH, Valerie J, Lund VJ, Niparko JK, Richardson MA, et al., editors. Cummings Otolaryngology Head and Neck Surgery. 5th edition. Philadelphia, PA: Mosby-Elsevier: p. 27612777.

4. Rimmer J, Giddings CE, Weir N. History of myringotomy and grommets. J Laryngol Otol. 2007 Oct; 121(10): p. 911-916.

5. Division of Pediatric Otolaryngology. Bilateral myringotomy and tubes. Children's Hospital of Pittsburgh of UPMC One Children's Hospital Drive 4401 Penn Ave. Pittsburgh, PA 15224. [cited 2014, September] Available from: http://www.chp.edu/CHP/Bilateral+Myringotomy

6. Network Medical Products Ltd. Coronet House, Kearsley Road, Ripon, North Yorkshire HG4 2SG, UK. [cited 2014 Feb 9]. Available from:http://www.networkmedical.co.uk/ent_ventilation_ tubes.html

7. Maroonroge S, Emanuel DC, LetowskiTR. Basic anatomy of the hearing system. In: Rash CE, Russo MB, Letowski TR. Schmeisser ET, editors. Helmet-Mounted Displays: Sensation, Perception and Cognition Issues. Fort Rucker, Alabama; US Army Aeromedical Research Laboratory. 2009 pp. 279-306. [cited 2009] Available from: http://www.usaarl.army.mil/publications/HMD_Book09

8. Fernando AF, Calavera KZ. Endoscopic Myringotomy and Ventilation Tube Placement: A Valuable Otolaryngologic Procedure under Topical Anesthesia. Philipp J Otolaryngol Head Neck Surg. 2012; 27 (1): 41-43.

9. Ritenour AE, Wickley A, Ritenour JS, Kriete BR, Blackbourne LH, Holcomb JB, Wade CE. Tympanic membrane perforation and hearing loss from blast overpressure in Operation Enduring Freedom and Operation Iraqi Freedom wounded. J Trauma. 2008 Feb;64(2 Suppl):S174 -S178. 